Raquel Guimarães Soares ${ }^{2}$

Ada Ávila Assunção ${ }^{3}$

Francisco de Paula Antunes Lima ${ }^{4}$

\section{A baixa adesão ao programa de ginástica laboral: buscando elementos do trabalho para entender o problema ${ }^{1}$}

\author{
Searching for elements at work that \\ could explain the low attendance to a \\ labor gymnastics program
}

\begin{abstract}
Resumo
Este artigo discute a implantação da ginástica laboral em uma central de teleatendimento e evidencia os efeitos da organização do trabalho sobre a atividade laborativa de atendimento. Buscou-se reunir elementos para analisar a baixa adesão ao Programa de Ginástica Laboral que foi implantado pelo Comitê de Ergonomia da empresa após a solicitação dos teleatendentes.

Os dados obtidos por meio de observação da atividade, entrevistas abertas e aplicação de questionário são aparentemente contraditórios, pois, apesar do reconhecimento da importância dos objetivos do programa pela maioria deles, o comparecimento às sessões de ginástica laboral (GL) sempre foi baixo. Viu-se que a implantação da GL sem reorganização do trabalho pode provocar constrangimentos aos trabalhadores. Os autores discutem as interações entre espaço físico e espaços social e organizacional no ambiente de trabalho e, ao final, apresentam parâmetros para o planejamento e seguimento dos programas de GL.
\end{abstract}

Palavras-chaves: atividade, ginástica laboral, organização do trabalho, Comitê de Ergonomia.

\begin{abstract}
This article discusses a labor gymnastics program implementation at a call center, evidencing the effects of labor organization on telemarketing work practices. It aims at understanding the reasons for the low participation in the program, which was implemented after the workers' request, by the company ergonomics committee.

The data obtained through field observation and semi-structured interviews were apparently contradictory, as attendance to the labor gymnastics sessions kept low, although most workers expressed very favorable opinions about the program. It was observed that the implementation of a gymnastic program without work reorganization might cause workers' hindrance. The authors discuss the interactions between physical ambiance, as well as social and organizational space. Finally, aiming at a more effective planning, other parameters for a gymnastic program are suggested.
\end{abstract}

Keywords: activity, labor gymnastics, work organization, ergonomic committee. 


\section{Introdução: histórico do setor antes da implantação do programa de ginástica}

O objetivo deste artigo é apresentar as dificuldades enfrentadas pelo Comitê de Ergonomia de uma empresa do setor público, por ocasião da implantação da GL no serviço de teleatendimento. A proposta surgiu no bojo da discussão dos resultados de um estudo ergonômico realizado na empresa com a finalidade de estabelecer recomendações de melhorias das condições ambientais e ergonômicas e de definir procedimentos operacionais coerentes com o intuito de preservar a saúde dos trabalhadores do setor. O estudo ergonômico foi realizado em 1999; as recomendações descritas abaixo começaram a ser implementadas em 2000 e o programa de ginástica foi implantado em 2001 e avaliado naquele mesmo ano, quando se constatou a não adesão dos trabalhadores.

\section{Descrição da função do teleatendente e do posto de trabalho}

O objetivo do serviço de teleatendimento é o registro das demandas, depois transmitidas às áreas comercial e operacional, bem como prestar informações solicitadas pelos clientes, disponibilizadas no sistema informatizado. São informações a respeito de contas e vazamentos de água, esgoto, recomposição de calçamento e asfalto, pedidos de ligações de água e esgoto, instalação de hidrômetro e leitura de contas da região metropolitana. O recurso técnico utilizado é o microcomputador, que está interligado em rede aos distritos operacionais e à área comercial da empresa. O teleatendente, portanto, tem pouco controle sobre o conteúdo das chamadas e sobre o momento em que elas acontecem, respondendo às demandas espontâneas variadas e variáveis ao longo do dia.

Os postos de trabalho, à época da análise ergonômica, não apresentavam qualquer possibilidade de regulação. As mesas não possuíam regulagem de altura e o espaço da superfície de trabalho era insuficiente para alocar os materiais utilizados durante o trabalho, como, por exemplo: DAC (Distribuidor Automático de Chamadas), aparelho de som do fone de ouvido, teclado, mouse, documentos para consulta etc. Não havia ainda apoio para os antebraços. As cadeiras não permitiam nenhum tipo de regulagem As teclas exigiam força dos dedos para a sua manipulação. Inexistiam apoios para os pés e suporte para monitor de vídeo, equipamentos que poderiam ajudá-los a manter uma postura menos estereotipada. A organização do trabalho será detalhada mais adiante (item 3) devido a sua importância para explicar a não adesão ao programa de GL.

\section{Resultados da análise ergonômica}

Por ocasião do estudo ergonômico, a atividade era caracterizada por uma sobrecarga muscular devido ao excesso de transcrições manuais, ao volume de dados digitados, às posturas desconfortáveis originadas pelas inadequações do posto de trabalho, à organização do trabalho (ritmo, pausas, jornada, hierarquia, falta de comunicação entre áreas de interface), gerando adoecimentos manifestados em sua maioria pelo estresse e pelas Lesões por Esforços Repetitivos/Doenças Osteomusculares Relacionadas ao Trabalho (LER/DORT).

O leiaute (em fileiras verticais, como em sala de aula) não facilitava a interação entre os atendentes, que se comunicavam com freqüência solicitando informações uns dos outros para agilizar o atendimento.

A central de teleatendimento tem uma interface direta com a área operacional e a área comercial pela própria natureza do trabalho, pois todos os serviços solicitados pelos clientes à central são efetuados por um destes setores. Mas a comunicação entre os setores não acontece. Durante as observações pôde-se verificar a insatisfação dos teleatendentes quanto ao funcionamento dos serviços, tanto operacionais quanto comerciais, cuja ineficiência comprometia os resultados do trabalho do atendimento.

Outro fator que começava a ser estudado à época era a implantação do software (único para as três áreas), que precisava de alterações, já que não estava atendendo satisfatoriamente às necessidades das três áreas.

No momento de devolução e validação dos resultados da análise ergonômica do trabalho, os trabalhadores expressaram o desejo de ter um programa de ginástica laboral aproveitando um dos intervalos de dez minutos, destinados às pausas implantadas após orientação do Comitê de Ergonomia. 
A GL foi incluída após sugestão dos trabalhadores, pois não constava do conjunto das recomendações iniciais. Os benefícios da implantação da GL dizem respeito à melhoria do funcionamento geral do aparelho musculoesquelético, sendo útil em situações de esforço postural estático exacerbado. No entanto, as análises do trabalho no teleatendimento evidenciaram outros constrangimentos (visuais, pressão de tempo, software, dimensões dos postos etc.) e formas específicas de adoecimentos causados pela repetitividade dos movimentos. Entendendo que a postura de trabalho é um meio e suporte da atividade, de modo geral, a ginástica tem efeito apenas paliativo, pois as múltiplas exigências da situação de trabalho influenciam na dinâmica dos arranjos posturais (ver item 2 do presente artigo). Sob esses preceitos, a intervenção ergonômica não indicou a GL por entender que, no caso de teleatendimento, não teria grandes efeitos preventivos em face à complexidade da exposição aos riscos de adoecimento.

Por outro lado, diante das demandas dos trabalhadores e como as recomendações propostas ao final da análise ergonômica prévia à introdução da ginástica (mudanças de mobiliário, introdução de novo software, mudança de leiaute e de espaço físico, reuniões periódicas entre as áreas de interface, introdução de treinamento voltado à realidade do atendimento) estavam em fase de implementação, entendeu-se que o programa de ginástica não seria algo isolado nem solução para "todos os males". Além do mais, mesmo que os efeitos benéficos da ginástica não estejam comprovados para prevenção das LER/DORT, sua adoção traz benefícios secundários, o que justifica, per se, sua adoção. O Comitê de Ergonomia apresentava também argumentos quanto aos limites de medidas como a ginástica laboral ou educação postural, reunindo elementos para afirmar que essas medidas não seriam suficientes para prevenir as LER/DORT, as depressões, as crises de ansiedade, as dores no pescoço, coluna, ombros, braços e mãos.

\section{O programa de ginástica laboral}

A proposta de ginástica na empresa foi implementada por uma empresa contratada, dois anos após a análise ergonômica do setor. A demora se deu em virtude do contexto político vivenciado pela empresa à época e, quando ele foi efetivamente implantado, a maioria dos trabalhadores que solicitaram a implantação do programa já não se encontravam no setor. Diante da mudança dos efetivos, uma nova consulta foi realizada à época do treinamento introdutório dos trabalhadores, por solicitação dos coordenadores do setor, na expectativa de que a implementação da ginástica diminuiria as queixas de dores registradas. Em nenhum momento o corpo gerencial tolhia a participação dos teleatendentes ou influenciava a decisão da não adesão. Assim, pelo menos no âmbito intersubjetivo, a chefia não criava obstáculos para que a pausa fosse aproveitada e, conseqüentemente, que fosse ocupada com a ginástica.

O Comitê de Ergonomia adota como princípio garantir a cada trabalhador a livre adesão ao programa proposto, entendendo que o uso do corpo é uma decisão que cabe a cada trabalhador individualmente. $\mathrm{O}$ trabalhador tinha direito à pausa, mas não a obrigatoriedade de ocupar este tempo com a ginástica.

As mudanças materiais e organizacionais em processo de implementação não dispensavam a introdução do programa de GL, em voga no momento de realização do estudo ergonômico. Além disso, as melhorias ergonômicas (novo software, leiaute e mobiliário, pausas e treinamento introdutório), com efeitos sensíveis na carga de trabalho imediata, ainda não deixavam gerentes e trabalhadores completamente seguros de que os efeitos de longo prazo seriam evitados. Alguns teleatendentes já tinham a experiência da GL nos locais onde trabalhavam anteriormente e a julgavam benéfica, outros aderiram à idéia considerando-a adequada, já que sabiam dos afastamentos dos colegas que os antecederam. Globalmente, a tarefa permanecia a mesma, sobretudo pelo fato da gerência não ter relaxado os constrangimentos de tempo, os quais, acreditava-se, seriam amenizados pelas melhorias do software.

A questão que se coloca é a seguinte: por que pessoas que voluntariamente solicitam ou aceitam participar de um programa de GL, quando lhes é oferecida essa possibilidade, não realizam os exercícios? Não se trata, aqui, de discutir se a GL é de fato útil ou não para prevenir LER/DORT ou se as outras mudanças ergonômicas a tornam dispensável, mas sim as razões da não adesão dos trabalhadores, quando, aparentemente, havia condições favoráveis para que o programa desse certo. 


\section{A prática da ginástica laboral e a ergonomia}

A GL aparece na literatura como uma das medidas para o enfrentamento de distúrbios físicos e emocionais na saúde do trabalhador, tais como: LER/DORT, estresse, lombalgias etc. Tem como objetivo "a prevenção e reabilitação das doenças que o trabalho repetitivo e monótono pode acarretar aos trabalhadores" (MENDES \& LEITE, 2004, p. 3).

Os autores divergem quanto à origem da GL. Alguns acreditam que sua procedência é japonesa, outros defendem que nasceu na Suécia (ZILLI, 2002). No Brasil, sua difusão ocorreu na segunda metade da década de 1980, com uma adesão ainda maior nos anos 1990, coincidindo com a "epidemia" das LER/DORT e com as práticas da qualidade total adotadas em inúmeras empresas, inclusive na estudada. A GL, naquela época, foi introduzida com finalidades diversas: prevenção de doenças ocupacionais, diminuição dos acidentes de trabalho, aumento da produtividade, melhora do bemestar geral dos trabalhadores (ZILLI, 2002; MENDES \& LEITE, 2004; SESI, 2002; MILITÃO, 2001). É uma atividade coletiva que deve levar em consideração as características individuais do trabalhador.

A GL pode ser de três tipos, conforme os momentos em que acontece e seus objetivos: (1) preparatória (no início do expediente): visa ao aquecimento, à preparação da musculatura e das articulações que serão utilizadas no trabalho, prevenindo acidentes, distensões musculares e doenças ocupacionais; (2) compensatória (no meio do expediente): previne a fadiga naqueles que realizam movimentos repetitivos, atividades com sobrecarga muscular ou, se o ambiente é estressante, tem o objetivo de diminuir as tensões musculares provocadas pelo trabalho; e (3) relaxante (no fim do expediente): é mais indicada para quem atende ao público, para extravasar as tensões acumuladas nas diversas regiões do corpo (MENDES \& LEITE, 2004).

Durante a pesquisa bibliográfica, não se encontrou nenhum estudo epidemiológico comprovando os efeitos da GL na prevenção de doenças relacionadas ao trabalho nem fundamentação teórica sobre os seus alcances e limitações. Os teóricos que pesquisam e implementam a ginástica laboral são unânimes em afirmar que os distúrbios de saúde dos trabalhadores ocasionam-se na organização do trabalho (pressão, rit- mo, tarefas fragmentadas, monotonia etc.) (ZILLI, 2002; MENDES \& LEITE, 2004; SESI, 2002; MILITÃO, 2001), mas, quando elaboram os programas ou descrevem seus resultados, parecem não levar em consideração tais fatores e a aplicam independentemente de uma análise mais aprofundada do problema e do contexto em que ele se coloca.

De modo geral, o que se verificou, tanto na literatura quanto no caso analisado, foram exercícios justificados de acordo com a saúde geral, sem os relacionar com as exigências específicas do trabalho que as pessoas realizam. É verdade, enquanto princípio geral, que "a musculatura do abdômen precisa ser forte, pois tem a responsabilidade de estabilização do quadril para garantir uma boa postura” (MILITÃO, 2001, p. 15). No entanto, a situação de trabalho oferece condições para se adotar essa "boa postura"?

A dificuldade de implantação da GL, segundo alguns autores (CAÑETE, 1996, apud MILITÃO, 2001), é de responsabilidade dos profissionais que não a planejam como deveriam: "a GL pode fornecer todos esses benefícios, dependendo da competência, grau de conscientização e postura ética adotada pelos profissionais que a conduzem” (MILITÃO, 2001, p. 34). Ou também da influência negativa dos trabalhadores, quando são "descomprometidos" e não aceitam a "melhoria”, não entendem a importância da GL (MENDES \& LEITE, 2004). Quando os resultados esperados não se concretizam, surgem especulações a partir dessas pré-concepções e não se investigam as causas reais.

Como já foi dito, os distúrbios da saúde estão vinculados ao trabalho, portanto, os programas de prevenção precisam priorizar esse aspecto e atuar levando em consideração as especificidades da atividade de trabalho. Para a ergonomia, os problemas osteomusculares, a melhoria da produção, o conteúdo das tarefas e o ambiente de trabalho não podem ter seus efeitos resumidos a uma única forma de prevenção, pois essa abordagem reducionista da situação de trabalho, pontual e diretiva, não considera o comportamento, as reais posturas no trabalho, bem como os determinantes das situações em que as pessoas trabalham.

A análise ergonômica do trabalho (AET), metodologia francesa de interven- 
ção e estudo das situações de trabalho, tem como centro a análise da atividade do homem e integra conhecimentos psicofisiológicos para recomendar melhorias e identificando elementos críticos sobre a saúde do trabalhador.

A AET ultrapassa as relações simplistas de causa e efeito. A principal diferença entre a abordagem ergonômica e a GL é que a primeira propõe medidas de prevenção a partir do que fazem os trabalhadores para proteger a sua própria saúde contra os riscos presentes nos locais de trabalho (ASSUNÇÃO, 2001) e a segunda apresenta uma gama de exercícios físicos que preparam o trabalhador:

para as atividades laborais diárias, ativando a circulação geral e o aparelho respiratório, além de preparar as estruturas musculoligamentares de forma que os funcionários fiquem menos propensos a problemas de saúde. (MILITÃO, 2001)

No primeiro caso, o foco é a relação entre o trabalhador e a situação de trabalho, espaço onde se desenvolve uma atividade orientada por objetivos específicos, cuja realização se serve do corpo como um meio.

O ponto forte dessa abordagem é a análise minuciosa do comportamento dos homens em situações de trabalho, que permite identificar e eliminar as causas mediatas de acidentes, de doenças e de sobrecarga de trabalho que geram situações penosas. (LIMA, 2000)

Na GL, o corpo aparece como um fim em si mesmo e objeto direto da intervenção do especialista. No entanto: em situações de trabalho, a postura não é um fim em si mesmo, como faz supor a prática de "educação postural". Durante a realização de um trabalho, as exigências da tarefa e a atividade em curso tendem a prevalecer sobre a "consciência corporal". De certa forma, estar envolvido com um trabalho que exige atenção ou pressa requer que esqueçamos do corpo próprio, fixando a consciência no trabalho, seus instrumentos e objetos. O corpo e a postura se tornam meios de uma atividade finalizada, que entra em conflito e se sobrepõe à autoconsciência ou mesmo às percepções do corpo próprio. (LIMA, 2000)

Evidenciou-se, com a revisão bibliográfica e diante da prática da ergonomia, que a prevenção necessita de medidas complexas e que medidas isoladas e desarticuladas são inócuas para evitar doenças relacionadas ao trabalho.

Ao revelar as relações da postura e do uso do corpo com o contexto organizacional, torna-se necessário estabelecer um espaço de negociação entre trabalhadores, empresários e profissionais que estudam o trabalho para definir critérios de ação em todos os aspectos relevantes para explicar essas relações, viabilizando, assim, uma alternativa efetiva de prevenção, inclusive a GL, mas não exclusivamente:

A centralização no homem, que caracteriza a prática de programas de exercícios laborais, não atende aos princípios básicos da ergonomia, dentro do contexto mais amplo de adaptação do meio ao homem. (LONGEN, 2003)

\section{As características da organização do trabalho na central de teleatendimento ${ }^{5}$}

Os processos de organização do trabalho na central de teleatendimento, onde os empregados se sentem pressionados pelo ritmo do cliente (que quer condicioná-los a um tempo maior de atendimento, com características personalizadas) em contraposição à empresa (que "exige" deles um tempo padrão de atendimento, já que "a boa" produtividade é determinada pelo número de ligações/atendente), além de pressões advindas de suas próprias exigências pessoais e de seu grupo de trabalho, colocam o trabalhador sob exigências contraditórias.

Os atendentes, após 50 minutos de trabalho, fazem uma pausa de 10 minutos. É prevista uma compensação do período de pausa, caso a última chamada não se resolva em tempo hábil. Tanto a pausa quanto o tempo destinado a cada chamada são controlados pela gerência, que divulga, na intranet e nos quadros de avisos, gráficos mostrando o desempenho individual dos trabalhadores. Esse tipo de monitoramento é fonte de pressão e causa constrangimentos extras para os atendentes (MASCIA \& SZNELWAR, 2000). O bom desempenho, tal como definido pelos gestores - tempo de atendimento máximo de dois minutos -, é valorizado por meio de vantagens indiretas, como prioridade na escolha de datas para gozo de férias, preferência na escolha dos feriados e dos fins de semana de folga.
${ }^{5}$ Este item faz alusão à monografia de conclusão do curso de Análise Ergonômica do Trabalho elaborada por Leal \& Soares, 1999. 
A variabilidade das demandas de serviço desse processo de trabalho contribui para a não utilização de uma fraseologia rígida, obrigatória, mas se espera que o atendimento seja objetivo. Essa exigência de objetividade desconsidera a variabilidade do conteúdo de cada chamada e a amabilidade e a cordialidade que cada usuário espera do atendente. A exemplo das afirmativas de diversos autores (VILELA \& ASSUNÇÃO, 2004; MARINHO, 2004; MASCIA \& SZNELWAR, 2000), as metas de quantidade se sobrepõem ao objetivo de qualidade do atendimento e satisfação do cliente.

Existem variados instrumentos de controle da produtividade: o instrumento de trabalho (distribuidor automático de chamadas), que emite um alarme luminoso durante a maior parte do tempo, sinalizando as chamadas que estão na espera; o cliente que busca prolongar o tempo da ligação até garantir a execução do serviço solicitado; $\mathrm{o}$ atendente que procura resolver o problema do cliente ou "se livrar" dele; e as bases quantitativas sobre as quais são estabelecidos os critérios de eficiência e eficácia do atendimento ao cliente. No geral, configura-se um quadro já exposto por Wisner (1994): a solicitação da memória imediata, as microdecisões, as exigências conflitantes, as pressões temporais e o contato com o público, às vezes agressivo, como fatores que levam à auto-aceleração.

A exigência de rapidez é um fator que torna difícil a relação com os clientes, deixando o atendente tenso e ansioso, o que faz com que suas respostas fiquem cada vez mais rápidas e mais secas. Foi observado em algumas situações que o cliente não se satisfaz com a informação dada e volta a ligar ou ainda exige na mesma ligação respostas mais claras, aumentando assim o número e o tempo dos atendimentos.

De fato, os trabalhadores sociais que fazem corretamente seu trabalho não raro têm uma carga cognitiva alta em razão das dificuldades de compreensão das reclamações do público, freqüentemente ignorante do jargão e das categorias administrativas. (WISNER, 1994)

A natureza do trabalho não permite a comunicação constante. Existe clara impossibilidade de conversas durante as atividades, restringindo as possibilidades de contato entre os trabalhadores para troca de informações úteis, como também destacado por Veras (2006).
As pressões inerentes às exigências do atendimento ao público são características da atividade de atendimento. A carga de trabalho advinda da interação com o cliente, a necessidade de se estabelecer um diálogo compreensivo, o confronto de situações conflitantes com as normas da empresa e a tentativa de convencimento mútuo exigem um esforço psíquico substancial (SOARES, 2005).

Trata-se de uma atividade que exige uma construção constante dos problemas tratados em função da grande quantidade de informações e dos processos cognitivos envolvidos, tais como: atenção, memorização, antecipação, tratamento e elaboração de informações, resolução de problemas e tomada de decisão. Isso vem ao encontro dos resultados obtidos na pesquisa de Echternacht (1998), em que foi verificado que essa atividade de comunicação mediada pelo meio técnico (informatizado) e o meio social (cliente) aumenta as exigências psicocognitivas.

Nesse contexto, a atenção às condições postas pelas políticas de gestão e estruturas organizacionais de um lado e as impossibilidades reais de regulação da carga de trabalho do outro trazem pressões no trabalho que se transvestem em queixas, dores e fadiga, tanto na esfera física quanto na mental. As condições materiais inadequadas de trabalho (equipamentos de informática, mobiliário e espaço físico) somadas a fatores organizacionais e psíquicos (a não execução do trabalho operacional, a falta de privacidade, a ausência de credibilidade e confiabilidade no setor de teleatendimento por parte dos usuários, a falta de resposta para o cliente, a desvalorização do trabalho do atendente e a conseqüente desvalorização pessoal por parte da hierarquia) podem ser consideradas como causas do adoecimento do atendente, causando estresse, crises nervosas, alterações de humor, insônia, angústia, falta de apetite, dificuldades no trabalho intelectual, isolamento, com interferência nas relações sociais e sintomas de LER/DORT. É freqüente atenderem ao telefone de casa com expressões cotidianas do trabalho, quadro clínico semelhante ao descrito por Le Guillant et al. (1984), a respeito da neurose das telefonistas. Para melhor ilustrar esta afirmação, algumas falas dos trabalhadores são exemplares:

"Em casa não consigo desacelerar."

"Não consigo dormir, à noite fico rolando de um lado para o outro, durmo pouco e acordo toda hora." 
"Isto aqui é fábrica de fazer louco."

No que tange ao distúrbio físico, as LER/ DORT ocupam o primeiro lugar em termos de prevalência. Além dos fatores biomecânicos já mencionados, como a inadequação do mobiliário e das condições de trabalho, os fatores técnico-organizacionais descritos acima podem estar associados aos problemas musculoesqueléticos. De acordo com Theorell (1996), os fatores psicossociais podem estar associados a problemas osteomusculares, pois já foi observado que tanto exigências físicas quanto psicológicas interagem de várias formas, contribuindo para o aumento na atividade elétrica muscular.

\section{Procedimentos de avaliação do programa de ginástica laboral}

Planejado por profissionais especializados em educação física, o programa de ginástica introduz a prática de atividades físicas em grupo durante a jornada de trabalho, com duração média de 10 minutos, em um pátio externo, ao lado da sala onde eles trabalham diariamente. O programa prevê o envolvimento de alguns trabalhadores do setor, treinados especificamente para agir como facilitadores na execução da ginástica. Os técnicos treinam e supervisionam os facilitadores dos grupos de ginástica uma vez por semana. Também uma vez por semana, o técnico acompanha os exercícios realizados pelos atendentes. Esses exercícios são modificados uma vez por mês, ou de 15 em 15 dias, caso necessário. Foi estabelecido pelos coordenadores do setor que o programa (projeto piloto) seria realizado nos turnos diurnos (manhã e tarde), nos quais trabalha a maioria dos teleatendentes $(87 \%)$.

Após quatro meses de implantação, o programa não havia conseguido a adesão dos trabalhadores que atuam na central de teleatendimento. Tentando entender suas razões, os idealizadores optaram por fazer uma pesquisa utilizando-se de um questionário auto-aplicado contendo cinco perguntas (ver Quadro 1) cujos resultados serão descritos abaixo. O turno da manhã foi escolhido para obter uma resposta rápida, pois se tentava melhorar o programa em tempo real e esta amostragem garantia representatividade estatística (59\% dos trabalhadores incluídos no programa piloto).

O questionário foi entregue aos atendentes durante uma das pausas. Alguns responderam no mesmo momento e outros pediram para entregar no dia seguinte (o que foi permitido). O percentual de respostas da amostra foi de $100 \%$.

Esse instrumento padrão, elaborado pela própria empresa que fornece os serviços de GL, é utilizado para avaliação sistemática do programa junto aos participantes. Além desse procedimento padrão adotado pela empresa, o Comitê de Ergonomia realizou sua própria avaliação por considerar inconclusivas as respostas fornecidas pelo questionário. Foram realizadas visitas in loco, observações sistemáticas e entrevistas abertas com os trabalhadores do turno diurno, o encarregado do setor e o supervisor da área com o objetivo de obter dados qualitativos que esclarecessem a não adesão ao programa.

\section{Resultados da avaliação do programa de ginástica laboral}

Quarenta e seis teleatendentes ocupavam a central de teleatendimento no momento da pesquisa (turnos: manhã, tarde, noite e madrugada). Foi escolhido pela empresa prestadora do serviço o turno da manhã para realização da pesquisa por concentrar o maior número de trabalhadores: 23 atendentes. Embora todos tenham respondido que a ginástica é necessária, e 22 teleatendentes (96\%) tenham afirmado acreditar nos benefícios do programa, a maioria (19 - 83\%) respondeu não participar das sessões de ginástica.
Várias justificativas foram arroladas pelos trabalhadores para não freqüentarem o programa:

"Só temos ajuda quando os técnicos da prestadora de serviços ou da Ergonomia estão por aqui."

"O horário que eu consigo desligar o telefone muitas vezes não coincide com o horário que os colegas iniciam a ginástica."

"Nunca há pessoas fazendo ginástica no meu horário de pausa."

"Eu já faço constantemente na academia." 
Quadro 1 Questionário de avaliação da ginástica laboral utilizado pela empresa responsável pelo programa.

Qvaliação do Programa Ginástica na Empresa
Questões:
1. Você participa da ginástica?
( ) sim ( ) não
2. A ginástica para vocêé:
( ) necessária ( ) desnecessária
3. Você pratica alguma atividade física regulamente?
( ) sim $\quad$ ( ) não
4. Você acredita que o Programa pode proporcionar benefícios?
( ) sim $\quad$ ( ) não
5. A ginástica significa para você:
( ) Lazer
( ) Relaxamento
( ) Prazer
( ) Tarefa
( ) União com colegas
( ) Obrigação
( ) Estímulo
( ) Prevenção
Sugestões:

"Pouco tempo de ginástica. Acho que o benefício é mínimo."

Quando questionados a respeito da prática de ginástica fora do horário de trabalho, 13 (57\%) entrevistados afirmaram realizar uma atividade física regularmente, o que pode explicar parte das ausências, sobretudo quando se consideram algumas das falas acima ("Eu já faço constantemente na academia"; "Pouco tempo de ginástica. Acho que o benefício é mínimo”). Quem se exercita regularmente não percebe os supostos benefícios da GL, o que revela uma falha do programa, que não conseguiu mostrar a diferença específica da GL em relação aos exercícios físicos de academia (musculação etc.), que podem ser escolhidos e direcionados para o fim que deseja quem os pratica, cujos objetivos são diversificados: perda de peso e da porcentagem de gordura corporal, redução da pressão arterial em repouso, melhora do diabetes, diminuição do colesterol total, melhora da flexibilidade, fortalecimento dos ossos e das articulações, estética etc. Essa diferença não foi abordada explicitamente nas preleções feitas no início do programa pelos instrutores aos trabalhadores, que, assim, fazem inferências a partir unicamente de sua experiência, nem sempre embasadas em conhecimentos técnicos.
Esses trabalhadores, pessoalmente motivados para fazer atividades em academias, não estavam convencidos de que a GL poderia trazer algum benefício.

Por outro lado, foram feitas várias sugestões para melhorar o programa, o que reafirma o interesse dos trabalhadores em fazer com que a ginástica funcione. Os trabalhadores comentaram e/ou propuseram:

"Fazer ginástica com música."

"Cobrar junto aos escolhidos para instruirnos, já que não há como vocês estarem sempre presentes, aliás, nem sei quais são eles."

"Acompanhamento com as instrutoras diariamente."

"Mais intensidade e mais alongamentos."

“Tem que ser diariamente, mais vezes e mais horários, até a turma acostumar, nos primeiros meses precisa de um acompanhamento, ou seja, um empurrãozinho."

"Um horário fixo para que todos possam fazer juntos."

“Ter pessoa efetivamente responsável para coordenar a ginástica já que se torna quase inconstante, digo, fica esquecida quando fica por conta dos divulgadores do teleatendimento." 
"Precisa ter uma pessoa responsável para o bom funcionamento e desenvolvimento desta atividade que nos beneficia."

"É preciso ser obrigatório."

"Acho que é pouco tempo de ginástica para apresentar um bom resultado."

A maior parte dessas sugestões remete à necessidade de motivar as pessoas (música, grupo, orientação, acompanhamento...) e de vencer as resistências iniciais, desenvolvendo o hábito da atividade física.

\section{Discussão}

Uma primeira explicação a ser avaliada para a recusa da ginástica refere-se à exposição pública quando se faz uma atividade física. A ginástica laboral é um momento de intimidade. Alguns trabalhadores, por razões e sentimentos pessoais, sentem-se demasiadamente expostos quando começam a fletir o tronco, estirar as pernas, massagear os dedos frente aos colegas de trabalho. Em outras empresas, sobretudo em setores de atendimento ao público externo, o programa de GL foi inviabilizado porque os trabalhadores julgaram ser moralmente condenável interromper sua atividade para fazer a "pausa para ginástica” enquanto os clientes aguardavam na fila. Essa "pressão social” acontece com as pausas em geral. Alguns trabalhadores de atendimento preferem não usar seu direito de repouso durante a jornada de trabalho. Embora essa seja uma explicação plausível, revelada por outros estudos (LIMA, 1997; SOARES, 2005), não foi manifestada neste caso, talvez pelo fato da ginástica ser realizada em espaço não exposto a público externo.

As respostas ao questionário e às entrevistas abertas mostram que as razões da recusa da GL, embora comuns, são hierarquizadas segundo a singularidade de cada indivíduo. $\mathrm{O}$ fato de ter sido realizada a pesquisa com uma amostragem (teleatendentes do turno da manhã) impossibilita associar a cada um o que pesou em sua decisão, mas oferece uma apreciação global da situação. Assim, apoiando-nos exclusivamente nos resultados das observações, das entrevistas abertas e do questionário, algumas pistas investigativas podem ser descartadas (falta de motivação e resistência à mudança) e outras explicações para a baixa adesão ao programa podem ser sugeridas:

1) instabilidade no emprego;
A maioria dos trabalhadores (21) evocou o relaxamento quando perguntados sobre o significado da ginástica.

Para sete trabalhadores, a ginástica significa lazer, para oito, prazer; apenas um deles disse que significa tarefa, outro funcionário afirmou se tratar de uma obrigação. Seis trabalhadores disseram haver união com os colegas, sete evocaram estímulo, e 16 disseram que a ginástica significa prevenção.

2) falta de orientação e acompanhamento dos instrutores;

3) falta de emulação social (dos instrutores e dos colegas);

4) não percepção dos benefícios da GL;

5) constrangimentos temporais decorrentes da natureza da atividade.

Atualmente, o setor vive um momento de mudanças na gestão de pessoal: a contratação de trabalhadores concursados para trabalhar junto aos estagiários contratados por tempo determinado. O grupo de trabalhadores que hoje integra o quadro funcional da área de teleatendimento não é o mesmo quando do início do estudo ergonômico, modificado por diferentes motivos: alto índice de turn over ocorrido no período, término do contrato temporário de trabalho, remanejamentos para outras áreas ou promoções ocorridas na empresa e, ainda, afastamentos ou demissões. Todas essas mudanças trazem uma sensação de instabilidade que conflita com a motivação para participar de uma atividade cujo maior benefício é de longo prazo. Os teleatendentes/estagiários se sentem inseguros diante das transformações que poderão culminar no seu desligamento da empresa. Sendo assim, estão preocupados e menos mobilizados para qualquer atividade coletiva cuja perspectiva é de longo termo. No entanto, quando questionados a respeito da GL, ainda assim manifestaram seu interesse, o que sugere que essa causa estrutural não seja suficiente para explicar a desmobilização.

Apesar da maioria dos atendentes terem respondido que consideram necessária a ginástica, na realidade ela só acontece quando a educadora física ou um integrante do Comitê de Ergonomia vai ao local. E, para isso, é preciso passar mais de uma vez 
no setor para lembrá-los da atividade coletiva. Os facilitadores voluntários não incorporaram o papel a eles destinado, ou seja, a proposta do grupo externo, responsável pela ginástica, de nomear um instrutor da empresa para divulgar, estimular e acompanhar os exercícios diariamente não vem surtindo os efeitos esperados. Segundo os instrutores, eles se sentem pouco à vontade ou com baixa capacidade para incentivar a ativa participação dos colegas, fazendo com que a atividade seja dependente da presença do instrutor. Não se trata apenas de exercer um papel de fiscalização (lembre-se de que a adesão é voluntária), mas também de emulação e de acompanhamento técnico, como transparece nas seguintes falas: "Cobrar junto aos escolhidos para instruir-nos"; "Acompanhamento com as instrutoras diariamente"; "Tem que ser diariamente, mais vezes e mais horários, até a turma acostumar, nos primeiros meses precisa de um acompanhamento, ou seja, um empurrãozinho"; "Um horário fixo para que todos possam fazer juntos”.

Outra situação que poderia explicar a baixa adesão seria a natureza das tarefas realizadas, pois em situações de forte solicitação musculoesquelética, como é o caso do setor analisado, com movimentos repetitivos e posturas estáticas prolongadas, a pausa pode ser mais desejada que a continuação dos exercícios, mesmo que sejam de outra natureza (alongamento, por exemplo). Não podemos esquecer dos efeitos do trabalho repetitivo sobre a saúde mental. Os estudos colocam em evidência que situações de sobrecarga manual/sobrecarga cognitiva (volume de informações a serem tratadas sob pressão temporal) podem gerar fadiga mental e que os trabalhadores preferem ter maior controle sobre o tempo da pausa (ASSUNÇÃO, 2001). A pausa não exerce apenas a função de regulação da fadiga fisiológica, mas também de regulação das cargas cognitiva e psíquica.

Como discutido anteriormente, vários trabalhadores não estavam convencidos da utilidade da GL, sobretudo em função de sua experiência com atividades físicas em academias. Além disso, o fato do setor estar implementando as recomendações ergonômicas contribui para o menor interesse pelo programa, como havia sido demonstrado em outra época, pois ficam mais fortes as medidas preventivas de caráter coletivo. A ginástica, ainda que seja realizada em grupo, é, na verdade, uma prevenção individual que exige uma motivação pessoal.
Se o grupo estudado considera a ginástica necessária e cerca da metade pratica regularmente alguma atividade física extra-trabalho, como explicar a baixa adesão?

Analisando o conteúdo das falas, vê-se que os trabalhadores parecem reproduzir o discurso dos defensores do programa, mas não estão convictos dos seus propósitos, uma vez que mencionam o caráter de tarefa e obrigação do mesmo. Trata-se aqui de uma ambivalência que guardaria uma relação com o objetivo imperativo do teleatendente de cumprir a sua missão. $\mathrm{Ou}$ seja, entre realizar o seu trabalho e fazer a ginástica, os trabalhadores optariam pelo primeiro, mesmo considerando possíveis benefícios da ginástica. Isso remete à discussão fundamental dos ergonomistas (GUÉRIN et al., 2001, DANIELLOU et al., 1989), segundo os quais parte das dificuldades para realizar os procedimentos previstos é conseqüência da maneira como o trabalho é organizado, da distância entre o prescrito e o real.

A implantação da ginástica no local de trabalho sem reorganizar o trabalho pode provocar constrangimentos aos trabalhadores. O caso das pausas diante dos tempos de atendimento é significativo: apesar do horário definido para todos os trabalhadores deixarem os postos, isso não acontece, pois os horários de término real da chamada não coincidem entre os trabalhadores, podendo acontecer com minutos de diferença. Ou seja, se o teleatendente estiver recebendo uma chamada, o momento de deixar o posto será adiado em alguns minutos. Para o programa, isso acarreta uma heterogeneidade no que se refere ao horário da ginástica, pois, na maioria das vezes, os teleatendentes não se integram ao grupo depois dos exercícios iniciados, reduzindo o número de adesões. A variabilidade da atividade de atendimento entra em conflito com a ginástica, que deve ser uma atividade coletiva e sincronizada: não é fácil se integrar ao grupo a qualquer momento, sem passar pelas fases iniciais.

Considerando a globalidade da inserção do ser humano na situação de trabalho, é possível pensar que o corpo, em suas dimensões física, cognitiva e psíquica, precisa desejar movimentar-se e descobrir-se para obter os ganhos da ginástica. Melhor, então, perguntar-se, antes de programar a ginástica, se há espaço físico e espaço social e organizacional no ambiente de trabalho para essas formas de expressão. 


\section{Conclusões}

As hipóteses e explicações aqui apresentadas poderão contribuir para orientar melhor os programas de ginástica laboral e aumentar a adesão voluntária dos trabalhadores. São inegáveis os ganhos quando se permite ao trabalhador tomar consciência de seu corpo. Porém, a consciência do corpo passa por uma aprendizagem, na qual algumas crenças e condutas são re-visitadas para serem des-construídas. E isso juntamente (imperativamente) com a correção da situação que provocou a postura estereotipada. Até o momento, devido às circunstâncias políticas e materiais, não foi possível implementar todas as medidas propostas ao final do estudo realizado no setor (LEAL \& SOARES, 1999). Cumpre lembrar que, por ocasião do I Seminário Interno de Ergonomia, destacou-se a relevância da continuidade da implantação do conjunto das recomendações para a melhoria nos processos de trabalho e, conseqüentemente, para a prevenção de doenças físicas e mentais dos trabalhadores.

Diante de todos os dados resultantes desta avaliação do programa de GL, sugere-se que a última chamada a ser atendida antes da pausa destinada à ginástica se dê três minutos antes da mesma, tempo médio dos atendimentos. Essa "simples" recomendação cria uma possibilidade real para realização da ginástica e manutenção do programa como é de interesse dos gerentes e dos trabalhadores. Essa possibilidade, ainda que real, não é condição suficiente para assegurar a adesão, que, como vimos, depende de uma mobilização subjetiva dos

\section{Referências bibliográficas}

ASSUNÇÃO, A. A. Os aspectos biomecânicos explicam os problemas musculoesqueléticos em trabalhadores expostos a tarefas repetitivas? In: CONGRESSO DA ASSOCIAÇÃO NACIONAL DE MEDICINA DO TRABALHO, 11, 2001, Belo Horizonte. Anais... Belo Horizonte: ANMT, 2001. CDROM.

DANIELLOU, F; LAVILLE, A; TEIGER, C. Ficção e realidade do trabalho operário. Rev. bras. saúde ocup., v. 17, n. 68, p. 6713, 1989.

ECHTERNACHT, E. A produção social das lesões por esforços repetitivos no atual contexto da reestruturação produtiva brasilei- trabalhadores, a começar pela crença de que a GL possa trazer algum efeito útil. Desse modo, o incentivo de colegas, instrutores e gerentes ganha uma base mais concreta e efetiva, deixando de ser puramente verbal ou moral. É necessário reconhecer aqui a contradição fundamental dessa forma de organização e do cálculo de produtividade baseado exclusivamente no critério "tempo de atendimento", que leva os gerentes a otimizarem o tempo, preenchendo todos os poros da jornada de trabalho, tornando meramente formal o incentivo para se fazer ginástica.

Baseados na evidência de campo, que mostra ocorrer uma invasão do tempo da ginástica pela última chamada atendida, perguntaríamos se o aparente paradoxo da totalidade de respostas afirmativas quanto à necessidade da ginástica e do dado real que mostra a baixa adesão não seria elucidado ao levar-se em conta o trabalho real. Ou seja, parece que o trabalho não permite e, às vezes, impede a adesão ao programa, mesmo que este seja formalmente estimulado pelos organizadores da produção. A ginástica, como qualquer outra recomendação ergonômica, deve nascer da análise detalhada dos constrangimentos e da variabilidade das situações reais de trabalho. Assim como um Equipamento de Proteção Individual (EPI) será deixado de lado se entrar em conflito com exigências do trabalho (qualidade, ritmo, eficiência...), a ginástica deve ser compatibilizada com as exigências do trabalho que gerou sua recomendação. ra. 1998. Tese (Doutorado em Engenharia de Produção) - Universidade Federal do Rio de Janeiro, Rio de Janeiro, 1998.

GUÉRIN, F. et al. Compreender o trabalho para transformá-lo: a prática da ergonomia. São Paulo: Edgard Blücher, 2001.

LEAL, L.; SOARES, R. G. Análise ergonômica do setor de teleatendimento de uma companhia de saneamento. 1999. Monografia (Curso de introdução à análise ergonômica do trabalho) - Faculdade de Medicina, Universidade Federal de Minas Gerais, Belo Horizonte, 1999.

Análise ergonômica em uma

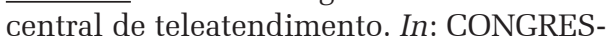


SO INTERNACIONAL DE ERGONOMIA, 10, 2000, Rio de Janeiro. Resumos... Rio de Janeiro: Abergo, 2000.

LE GUILLANT, L. et al. A neurose das telefonistas. Rev. bras. saúde ocup., v. 12, n. 47, p. 7-11, 1984.

LIMA, F. P. A. A ergonomia como instrumento de segurança e melhoria das condições de trabalho. In: SIMPÓSIO BRASILEIRO SOBRE ERGONOMIA E SEGURANÇA DO TRABALHO FLORESTAL E AGRÍCOLA (ERGOFLOR), 1, 2000, Viçosa. Anais... Viçosa: Universidade Federal de Viçosa/Fundacentro, 2000. p. 1-11.

LIMA, M. E. A. A LER no setor bancário. In: LIMA, M. E. A.; ARAÚHO, J. N. G.; LIMA, F. P. A. (orgs). Lesões por esforços repetitivos: Dimensões ergonômicas e psicossociais. Belo Horizonte: Health, 1997. p. 52-107.

LONGEN, W. C. Ginástica laboral na prevenção de LER/DORT? Um estudo reflexivo em uma linha de produção. 2003. Dissertação (Mestrado em Engenharia de Produção) - Programa de Pós-Graduação em Engenharia de Produção, Universidade Federal de Santa Catarina, Florianópolis, 2003.

MARINHO, S. A. A regulamentação das condições de trabalho no setor de teleatendimento no Brasil: necessidades e desafios. 2004. Dissertação (Mestrado em Saúde Pública) - Faculdade de Medicina, Universidade Federal de Minas Gerais, Belo Horizonte, 2004.

MASCIA, F. L; SZNELWAR, L. I. Diálogo e constrangimentos do script na atividade de atendimento a clientes. In: SZNELWAR, L.; ZIDAN, N. (org). O trabalho humano com sistemas informatizados no setor de serviços. São Paulo: Plêiade, 2000. p. 97104.

MENDES, R. A.; LEITE, N. Ginástica laboral: princípios e aplicações práticas. São Paulo: Manole, 2004.
MILITÃO, A. G. A influência da ginástica laboral para a saúde dos trabalhadores e sua relação com os profissionais que a orientam. 2001. Dissertação (Mestrado em Engenharia de Produção) - Programa de PósGraduação em Engenharia de Produção, Universidade Federal de Santa Catarina, Florianópolis, 2001.

SESI. Serviço Social da Indústria. Ginástica na Empresa. Disponível em: http:// www.sesi.org.br/Programas/ginastica.htm. Acesso em: 2002.

SOARES, R.G. Da dor ao riso: a relação de serviço entre saber fazer e saber atender. 2005. Dissertação (Mestrado em Engenharia de Produção) - Escola de Engenharia de Produção, Universidade Federal de Minas Gerais, Belo Horizonte, 2005.

THEORELL, T. Possible mechanisms behind the relationship between the demandcontrol-support model and disorders of the locomotor system. In: MOON, S. D.; SAUTER, S. L. Beyond biomechanics: psychosocial aspects of musculoskeletal disorders in office work. London: Taylor \& Francis, 1996. p. 65-73.

VERAS, V. S. Relações sociais de trabalho e custo humano da atividade: vivências de mal-estar e bem-estar em serviço de teleatendimento governamental. 2006. Dissertação (Mestrado em Psicologia), Universidade de Brasília, Brasília, 2006.

VILELA, L. V. O.; ASSUNÇÃO, A. A. Os mecanismos de controle da atividade no setor de teleatendimento e as queixas de cansaço e esgotamento dos trabalhadores. Cad. Saúde Pública, v. 20, n. 4, p. 10691078, 2004.

WISNER, A. Organização do trabalho, carga mental e sofrimento psíquico. In: inteligência no trabalho: textos selecionados de Ergonomia. São Paulo: Fundacentro, 1994.

ZILLI, C. M. Manual de cinesioterapia/ ginástica laboral: uma tarefa interdiscipli- 